\title{
Interval Estimate of the Threshold and the Poverty Rate by the Methods of the Simulation
}

\author{
Boudjelal Boukaabar $^{1} \&$ Mohamed Kheireddine Dellil ${ }^{1}$ \\ ${ }^{1}$ Faculté des sciences économiques, des sciences commerciales et sciences de gestion, Oran Es-Senia University, \\ Oran, Algeria \\ Correspondence: Boudjelal Boukaabar, Faculté des sciences économiques, des sciences commerciales et sciences \\ de gestion, Oran Es-Senia University, Oran, Algeria. Tel: 213-6-6125-0758. E-mail: b.boudj@hotmail.fr
}

Received: February 3, 2012

Accepted: August 17, 2012

Online Published: September 3, 2012

doi:10.5539/ibr.v5n10p212

URL: http://dx.doi.org/10.5539/ibr.v5n10p212

\begin{abstract}
So far, the work and research on the evaluation of the threshold and the poverty rate were satisfied with obtaining a point estimator of these parameters. This assessment is obtained always from a sample of the population whose parameters are under study. In Statistics, such an approach raises the issue of confidence which may be linked to estimators from a sample and used in place of the unknown population parameters. Statisticians rightly consider that no confidence can be given to the point estimators and propose instead using interval estimates. A problem arises if one was to calculate confidence intervals for the parameters that are the poverty threshold and rate: the data. We need a fairly large number of samples from which we calculate the estimators for both parameters. It is only then that we can make a thorough statistical study to estimate confidence intervals for each of the two unknown parameters. Although theoretically this approach does not suffer from any criticism by statisticians, it could prove costly since it requires taking several samples. Moreover, it could be simply unenforceable because requiring probing a large number of individuals to uncover their financial situation. In some societies, it is seen to be awkward to reveal one's income. Such mentality is current in the Algerian society. This paper proposes a new methodology that solves the problem of the data requirement. This methodology uses the theory of simulation and has the advantage of requiring taking only a single sample. From this base sample we derive the laws of probability needed for the generation of several samples by a computer simulation. Each resulting sample will be used to compute the poverty threshold and the poverty rate attached to it. The collection of these estimators will be used for statistical analysis to evaluate a confidence interval for the threshold and the poverty rate of the original population from which the sample was taken.
\end{abstract}

Keywords: poverty, poverty rate, poverty threshold, confidence interval, simulation

\section{Introduction}

The economic literature is replete with research papers on the topic of measuring poverty. We can mention without being exhaustive the works of Foster J.E, Greer J. and Thorbecke E. (1984), Ravallion M. (1992), Sen A.K. (1976;1983), Townsend P. (1962). In Algeria this topic has been treated by Laabes B. (2001), Belahcen H. (2005) and Bendraoua N. (2010).

The assessment of poverty requires the resolution of several issues including the definition of poverty. It is generally accepted that an individual is considered to be poor if his/her income does not allow him/her the satisfaction of basic needs. Already, this definition raises two questions:

- What is an income?

- What is a basic need?

The income considered is the annual cash income net of tax and social security. It includes earned income such as salaries or fees of the liberal professions, property income (income from apartment rentals etc.) and income as social pensions. Income covers therefore tangible returns easily translated into monetary terms. Intangible income received in kind, such as the fact of living in free housing offered by the employer are often not taken into account. However, some researchers do not stop at the mere notion of monetary income and consider any income which could improve the lives of those who benefit; be it tangible or intangible. In this case, we will talk of an expanded income. From this perspective, the benefits such as free rent housing are evaluated in monetary terms. 
The definition of poverty as advanced in the preceding paragraph considers individuals. However, the income, is often given or evaluated for the whole household. If young children generally do not receive income, they still remain poor if the parents are actually poor as we cannot consider the children as poor if their parents are wealthy. Hence the adoption of a simple principle: if a household is poor, all of its individuals are poor and are at the same level. Such a principle is used by Glaude M. and Moutardier M. (1994). Now, since the expenditure of a household is not sustained in the same way by all its members, it is necessary to introduce an equivalence scale. Thus the Oxford scale considers that the head of the household counts as one unit of consumption, the spouse if there is one accounts for 0.7 units and children account for 0.5 units. The INSEE, the French institute for statistics and economic studies has adopted a different scale.

Once a consensus is reached on the definition of the income to be considered, we have yet to find a critical value of the income below which we can say that the most basic needs are not met and therefore the individual who receives such an income is to be considered as poor. In other words, we are posing the problem of assessing the poverty threshold. There are three types of poverty thresholds: absolute, relative or subjective as explained by Goedhart $\mathrm{T}$. et al (1977) and by Hourriez J.M, Legendre N. and Le Verre R. (2001).

A poverty threshold is called absolute if its determination involves the assessment of the costs of basic needs. The cost of food expenditure needed for survival in a healthy condition is estimated. To this estimator, we add the cost of non-food expenditures that are considered necessary for a decent life. Non-food expenditures include the cost of housing, health, education, transport etc... It goes without saying that determining the absolute threshold of poverty can be quite difficult. In addition, an absolute threshold of poverty for each country makes comparison between different countries impossible. For these reasons, other types of thresholds were developed. Note that the concept of absolute poverty line was developed by the U.S. in particular by Orshansky M. (1965).

A variant of the absolute poverty threshold was developed by the United Nations Program for Development in order to facilitate comparisons between different countries. A person is considered poor if his/her daily income is less than 1.25 dollars expressed in purchasing power parity.

Often, the poverty threshold is defined as a percentage of a parameter of the concentration of the income distribution. The concentration parameter most used is the median income and the percentage most often used is $50 \%$, although Europe intend to use $60 \%$ of the median as the poverty threshold as reported by Chanbaz C. (1997).

A threshold is called subjective if its determination depends on the answers made by a sample of the population Such a definition is given by O'higgins M. (1980).

To estimate the poverty rate in a given population we take a representative sample of this population and we compute the percentage of people whose income is below the poverty threshold.

Once, the poverty rate measured, a question arises: given that this rate is a statistic derived from a sample to estimate the actual population rate of poverty, what is our confidence in this point estimator? Statistical theory answers this question: the confidence is null as a statistic may take any value in its domain of variation depending on our choice of individuals to be entered in the sample. For our confidence to grow, we should take as an estimator, not a single value of the poverty rate but a range of values for this variable.

In order to assess a range that ensures a certain level of confidence, we must study the law of distribution of the random variable rate of poverty. This study requires to have at our disposal a number of realizations of this variable. However, the evaluation of only one value of the poverty rate demand an entire sample of observations of the individual incomes. In the case of poverty measurement, it is very expensive not to say impossible to obtain several samples of information as critical as income. This is true for any society but it is even more true in our Algerian society. Hence the question to know whether there is another method to obtain more evaluations of the poverty rate without resorting to a multitude of samples.

To this question the simulation theory responds positively. Thanks to the simulation, we can continue our study of the poverty rate using only one sample of observations.

This paper develops a methodology based on simulation and statistical analysis to evaluate a confidence interval for the threshold and the poverty rate. The methodology is based on the derivation of the laws of probability distribution of the following variables:

- Income,

- The number household individuals,

- And the presence or absence of a spouse. 
This derivation is made from a sample of observations of the income. Once defined the laws of distribution, we generate by simulation a large number of samples in accordance with these laws. Each of these samples is used to evaluate a threshold and a poverty rate. A statistical study can finally be realized on the collection of statistics that are the threshold and the rate. From the study we can estimate confidence intervals for these statistics.

\section{Simulation Theory}

This section lays the theoretical foundations needed to write computer programs to perform the simulation. First, we must calculate the probabilities that underlie the generation of the observations. By observation we mean a ordained triplet: the total income of the household; the number of people in the household and last the marital status of the household head. For this, we group the observations of the sample by class of income and the number of individuals in the household into two separate tables. The first table holds the data relative to the households whose heads are married, the second one for the unmarried ones. For each table, the rows represent the income classes while the columns represent the number of people dependent on these heads of families.

Table 1. Grouping of the raw observations

\begin{tabular}{lllllll}
\hline Classes & 0 dependent & 1 dep. & 2 dep. & $\ldots \ldots \ldots \ldots$ & $\mathrm{n}$ dep. & class Total \\
\hline Class 1 & $\mathbf{O}_{10}$ & $\mathbf{O}_{11}$ & $\mathbf{O}_{12}$ & & $\mathbf{O}_{1 \mathrm{n}}$ & $\mathbf{O}_{1 .}$ \\
Class 2 & $\mathbf{O}_{20}$ & $\mathbf{O}_{21}$ & $\mathbf{O}_{22}$ & & $\mathbf{O}_{2 \mathrm{n}}$ & $\mathbf{O}_{2 .}$ \\
Class 3 & $\mathbf{O}_{\mathbf{3 0}}$ & $\mathbf{O}_{31}$ & $\mathbf{O}_{32}$ & & $\mathbf{O}_{3 \mathrm{n}}$ & $\mathbf{O}_{3 .}$ \\
$\ldots \ldots$ & & & & & \\
Class m & $\mathbf{O}_{\mathbf{m} 0}$ & $\mathbf{O}_{\mathrm{m} 1}$ & $\mathbf{O}_{\mathrm{m} 2}$ & & $\mathbf{O}_{\mathrm{mn}}$ & $\mathbf{O}_{\mathrm{m} .}$ \\
Total & $\mathbf{O}_{.0}$ & $\mathbf{O}_{.1}$ & $\mathbf{O}_{.2}$ & & $\mathbf{O}_{. \mathbf{n}}$ & $\mathbf{O} .$. \\
\hline
\end{tabular}

Classification of the observations by class of income and number of dependents.

We will use the following notation:

I: Index of an income class.

m: Number of income classes.

n: Number of columns or maximum number of dependent people.

j: index of a column representing a number of dependents.

$\mathbf{O}_{\mathrm{ij}}$ : number of heads of households whose income is included in class $\mathbf{i}$ and their number of dependents is equal to j.

$\mathbf{O}_{\mathrm{i}}$ : Total number of heads of households whose income is included in class $\mathbf{i}$. It is obtained by summing over all columns $\mathrm{j}$ the $\mathbf{O}_{\mathrm{ij}}$ 's for the ith class.

$$
\boldsymbol{O}_{i .}=\sum_{j=0}^{n} \boldsymbol{O} \boldsymbol{i j} \boldsymbol{i}=1,2 \ldots \mathrm{m}
$$

$\mathbf{O}_{\text {.J }}$ : Total number of heads of families with dependents $\mathbf{j}$. It is obtained by summing over all rows $\mathbf{i}$ the $\mathbf{O}_{\mathbf{i j}}$ 's of a column $\mathbf{j}$.

$$
\boldsymbol{O}_{. j}=\sum_{i=1}^{m} \boldsymbol{o} \boldsymbol{i j} \boldsymbol{j}=0,1,2 \ldots . \mathbf{n}
$$

O..: Grand total can be calculated as the sum of all $\mathbf{O}_{. J}$ or the sum of all $\mathbf{O}_{\mathbf{i} .}$.

$$
\boldsymbol{O} . .=\sum_{i=1}^{m} \boldsymbol{O} \boldsymbol{i} .=\sum_{j=0}^{n} \boldsymbol{O} . \boldsymbol{j}
$$

For the rest of our development, we shall note with a prime the variables relative to the table 1 concerning the married household heads while the variables of unmarried ones shall be noted normally. Thus we will note $\mathbf{O}_{\mathrm{ij}}, \mathbf{O}_{\mathrm{i}}$, $\mathbf{O}_{\mathrm{j} \text {. }}$ and $\mathbf{O}$.. to refer to the table of unmarried heads. We note $\mathbf{O}_{\mathrm{ij}}^{\prime}, \mathbf{O}_{\mathrm{i}, \mathrm{\prime}}^{\prime} \mathbf{O}_{\text {.J }}^{\prime}$ and $\mathbf{O}^{\prime . .}$ to refer to the same variables in the table of married heads.

Once these two tables achieved, the probability theory necessary for the conduct of the simulation can be developed.

\subsection{Calculating the Probability of the Income Class}

For a given class $\mathbf{i}$, we have $\mathbf{O}_{\mathbf{i}}$. Heads of families who are unmarried and $\mathbf{O}_{\mathbf{i} \text {. }}$ who are married. The total number of heads of families in the sample is equal to:

$$
\boldsymbol{N}=\boldsymbol{O} . .+\boldsymbol{O}^{\prime} .
$$

$\mathbf{p}_{\mathbf{i}}^{\mathbf{c}}$ the marginal probability of class $\mathbf{i}$ object of our attention is thus equal to: 


$$
\boldsymbol{p}_{\boldsymbol{i}}^{\boldsymbol{c}}=P[\text { class } i]=\left(\boldsymbol{O} \boldsymbol{i} .+\boldsymbol{O}^{\prime} \boldsymbol{i} .\right) / \boldsymbol{N}=\left(\boldsymbol{O} \boldsymbol{i} .+\boldsymbol{O}^{\prime} \boldsymbol{\prime} . \mathbf{}\right) /\left(\boldsymbol{O} . .+\boldsymbol{O}^{\prime} . .\right) \boldsymbol{i}=1,2 \ldots \mathbf{m}
$$

\subsection{Calculation of the Probability of the Marital Status}

The marginal probability of the marital status knowing the class $\mathbf{i}$ of income can be calculated as follows:

$$
\begin{aligned}
& \boldsymbol{p}_{\boldsymbol{i}}^{\boldsymbol{s}_{i}}=P[\text { married } \mid \text { class } \boldsymbol{i}]=\boldsymbol{O} \boldsymbol{i}_{\mathbf{i}} /\left(\boldsymbol{O} \boldsymbol{i}_{\mathbf{i}}+\boldsymbol{O} \boldsymbol{i} .\right) \boldsymbol{i}=1,2, \ldots \mathbf{m} \\
& \boldsymbol{p}_{\boldsymbol{i}}^{\boldsymbol{s}}=P[\text { non married } \mid \text { class } \boldsymbol{i}]=\boldsymbol{O} \boldsymbol{i} . /\left(\boldsymbol{O} \boldsymbol{i}^{\prime}+\boldsymbol{O} \boldsymbol{i} .\right) \boldsymbol{i}=1,2, \ldots \mathbf{m}
\end{aligned}
$$

Equation 7 above can also be deduced as:

$$
\boldsymbol{p}_{\boldsymbol{i}}^{\boldsymbol{s}}=P[\text { non married } \mid \text { class } \boldsymbol{i}]=1-P[\text { married } \mid \text { class } \boldsymbol{i}]=1-\boldsymbol{p}^{\boldsymbol{s}^{\prime}}{ }_{i}
$$

\subsection{Calculation of the Probability of the Number of Dependents}

for the unmarried heads of household, $\mathbf{p}_{\mathbf{i j}} \mathbf{e}_{\mathbf{j}}$ is the probability that the number of dependents is equal to $\mathbf{j}$ given that the income of the household lies in class $\mathbf{i}$. Similarly, let $\mathbf{p}^{\mathbf{e}^{\mathbf{i}}}{ }_{\mathrm{ij}}$ be the probability of the same event when the marital status of household head is married.

$$
\begin{aligned}
& \boldsymbol{p}_{i j}^{\boldsymbol{e}}=\boldsymbol{O} i \boldsymbol{j} / \boldsymbol{O}_{i .} \boldsymbol{i}=1,2 \ldots \boldsymbol{m}, \boldsymbol{j}=1,2 \ldots \mathrm{n} \\
& \boldsymbol{p}^{\boldsymbol{e}^{\prime}}{ }_{i j}=\boldsymbol{O}^{\prime} \boldsymbol{i j} / \boldsymbol{O}{ }^{\prime} \boldsymbol{i} . \boldsymbol{i}=1,2 \ldots \boldsymbol{m}, \boldsymbol{j}=1,2 \ldots \mathrm{n}
\end{aligned}
$$

\subsection{Methods for Generating Different Probabilities}

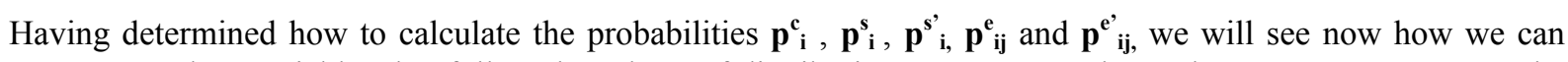
generate random variables that follow these laws of distribution. Suppose, we have chosen a person to enter the sample to be used to estimate the threshold and the poverty rate. For this, we need to know the income, the marital status and number of dependents of that person. We begin with the generation of income.

\subsection{Income Generation}

Income generation will be done in two steps. First we generate the income class in which the income will fall, then in a second phase we generate the income itself between the lower and upper bounds of the generated class.

\subsubsection{Determination of the Class}

To determine the simulated income class, we use the tabular method of generating a random number as explained in Fishman G.S. (1978). First we calculate the cumulative probabilities for each class of income. Let $\mathbf{P}_{\mathbf{i}}^{\mathbf{c}}$ be the

\begin{tabular}{|c|c|c|}
\hline Class index i & Class Probability & Cumulative Probability \\
\hline 1 & $\overline{p_{1}{ }_{1}}$ & $\mathbf{P}_{1}=\mathbf{p}_{1}{ }_{1}$ \\
\hline 2 & $\mathbf{p}_{2}{ }_{2}$ & $\mathbf{P}_{2}^{\mathrm{c}}=\mathbf{p}_{1}^{\mathrm{c}}+\mathbf{p}_{2}^{\mathrm{c}}$ \\
\hline $\begin{array}{l}\ldots \\
\mathrm{m}\end{array}$ & $\begin{array}{l}\cdots \\
\mathbf{p}_{\mathbf{m}}^{\mathrm{c}}\end{array}$ & $\mathbf{P}^{\mathrm{c}}{ }_{\mathrm{m}}=\mathbf{p}_{1}^{\mathrm{c}}+\mathbf{p}_{2}^{\mathrm{c}}+\ldots+\mathbf{p}_{\mathrm{m}}^{\mathrm{c}}=1$ \\
\hline
\end{tabular}
cumulative probability of class i:

where $\mathrm{p}_{\mathrm{i}}^{\mathrm{c}}$ is as given by equation 5 .

$$
\boldsymbol{P}_{i}^{c}=\sum_{j=1}^{i} \boldsymbol{p}_{i}^{c} i=1,2 \ldots \mathrm{m}
$$

Table 2. Cumulative probabilities of the income classes

How to compute the cumulative probabilities of the income classes?

Let $\mathbf{X}$ be the random number given by the random number generator. $\mathbf{X}$ is uniformly distributed on the interval $[0,1]$. The tabular method considers that the value of $\mathbf{X}$ is actually the value of the cumulative probability of the class of income. So, the class $\mathbf{i}^{*}$ selected by the random number generator is the first class that satisfies the following condition:

$$
\boldsymbol{P}_{i^{*}-1}^{c}<X \leq P_{i^{*}}^{c}
$$

Example: Let's suppose the value of $\mathbf{X}$ is 0.657 . $\mathbf{I}^{*}$ is the index of the first class of income whose cumulative probability is greater than or equal to the value of $\mathbf{X}$.

\subsubsection{Income Determination}

Once the income class known, we will have to assess more accurately the income of the household currently under study. We assume that the incomes in any class are uniformly distributed over the interval of that class. Since there are $\mathrm{m}$ income classes, each class interval is equal to: 


$$
\text { Interval }=(\text { maximum income }- \text { minimum income }) / m
$$

Let $\mathbf{a}_{\mathbf{i}}$ be the lower limit of class $\mathbf{i}$ and $\mathbf{b}_{\mathbf{i}}$ its upper limit.

$$
\begin{gathered}
\boldsymbol{a}_{\boldsymbol{i}}=\text { revenu minimum }+(i-1) * \text { interval } \\
\qquad \boldsymbol{b}_{\boldsymbol{i}}=\boldsymbol{a}_{\boldsymbol{i}}+\text { interval }
\end{gathered}
$$

A random variable $X$ follows the uniform distribution on the interval $\left[\mathbf{a}_{\mathbf{i}}, \mathbf{b}_{\mathbf{i}}\right]$ which we note $\mathrm{X} \sim \mathrm{U}\left(\mathbf{a}_{\mathbf{i}}, \mathbf{b}_{\mathbf{i}}\right)$ if its probability density function $(\mathrm{PDF})$ is:

$$
\begin{gathered}
P(X=R)=1 /\left(\boldsymbol{b}_{\boldsymbol{i}}-\boldsymbol{a}_{i}\right) \text { If } \mathbf{a}_{\mathbf{i}} \leq \mathrm{R} \leq \mathbf{b}_{\mathbf{i}} ; 0 \text { otherwise } \\
\text { And } P(X \leq R)=\int_{a i}^{R} d x /(b i-a i)=\left(R-\boldsymbol{a}_{i}\right) /\left(\boldsymbol{b}_{\boldsymbol{i}}-\boldsymbol{a}_{i}\right)
\end{gathered}
$$

The uniform law is one of the few laws of probability that can be easily simulated by inversion, see Fishman G.S. So, we will use this method to generate the income. The inversion method involves generating a random number and to equalize the number to the right side of the equation 16. Let $\mathbf{X}$ be a random number generated by the computer. Solving the following equation gives the value of $\mathrm{R}$

$$
\boldsymbol{X}=\left(R-a_{i}\right) /\left(\boldsymbol{b}_{\boldsymbol{i}}-\boldsymbol{a}_{i}\right)
$$

That is:

$$
R=\boldsymbol{a}_{\boldsymbol{i}}+\boldsymbol{X}^{*}\left(\boldsymbol{b}_{\boldsymbol{i}}-\boldsymbol{a}_{\boldsymbol{i}}\right)
$$

$\mathrm{R}$ is the desired income. Equation 18 gives the formula that translates into income the computer generated random number following the uniform distribution on the interval $\left[\mathbf{a}_{\mathbf{i}}, \mathbf{b}_{\mathbf{i}}\right]$.

Let's review how the income generation has been achieved according to the law of distribution as determined from the sample. We proceed in two steps:

1. First we determine randomly a class of income. For this we generate a random number $\mathbf{X}$ which will be used to decide the class in which the income will fall. The class chosen is that which satisfies equation 11 . Let $\mathbf{i}^{*}$ be the index of that particular class.

2. Once the class is known, we compute its lower and upper limits $\mathbf{a}_{\mathbf{i}^{*}}$ and $\mathbf{b}_{\mathbf{i}^{*}}$ according to equations 13 and 14 . A second random number $\mathbf{X}$ is obtained and the desired income $\mathrm{R}$ is estimated using the equation 18 .

Next, we need to evaluate the marital status of the household head.

\subsection{The Determination of the Marital Status}

In probability theory, a random variable that can take a value among two values is said to follow Bernoulli's law of probability. Usually one of the two values is called a success and the other one is considered a failure. The probability of success is denoted $\mathrm{p}$, that of the failure is denoted $\mathrm{q}$ with $\mathrm{q}=1-\mathrm{p}$.

The most appropriate method to generate random numbers that follow the Bernoulli distribution with $p$ as the probability of success is the so-called rejection method, of which Fishman G.S. gives a very thorough description. A random number $\mathbf{X}$ is generated by the computer. If $\mathbf{X}$ is less than or equal to the probability $\mathrm{p}$, we recognize that we are dealing with a success. Otherwise we are dealing with a failure.

In our case, if we consider the fact of being married as a success, the probability of success $p$ is simply $\mathbf{p}^{\mathbf{s}^{\mathbf{s}}}{ }_{\mathbf{i}}$ as calculated by equation 6 . Hence, if the random number $\mathbf{X}$ given by the computer is less than or equal to $\mathbf{p}^{\mathbf{s}^{\mathbf{s}}}{ }_{\mathbf{i}}$ the marital status obtained is "married", otherwise the status is "unmarried".

Finally, we need to see how to generate the number of people in the household.

\subsection{Generation of the Number of Dependents}

Equations 8 and 9 show us how to derive the probability associated with the number of dependent people knowing the class of income and the marital status of the head of a household. Again, we use the tabular method that we used to determine the income class.

Knowing the income class $i^{*}$ and the marital status that have been selected by the computer, we can calculate the cumulative probabilities associated with the number of dependents of the household. Table 3 shows how to compute these cumulative probabilities for the married household heads and table 4 does the same thing for the unmarried household heads. 
Table 3. Cumulative probabilities of the number of dependents case of a married household head

\begin{tabular}{|c|c|c|c|c|}
\hline Number of Dependents $\mathrm{j}$ & 0 & 1 & $\ldots \ldots$ & $\mathrm{n}$ \\
\hline $\mathbf{p}^{\mathbf{e}^{\prime}{ }_{i^{*} j}}$ & $\mathbf{p}^{\mathrm{e}^{\prime}{ }^{\prime}{ }^{\star} 0}$ & $\mathbf{p}^{\mathrm{e}^{\prime}{ }_{\mathbf{i}^{*} 1}}$ & $\ldots \ldots \ldots$ & $\mathbf{p}^{\mathbf{e}^{\prime}{ }^{\prime}{ }^{\star} \mathbf{n}}$ \\
\hline $\mathbf{P}^{\mathbf{e}^{\prime}{ }^{*}{ }^{*} \mathbf{j}}$ & $\mathbf{p}^{\mathbf{e}^{\prime}{ }_{\mathrm{i}^{*} 0}}$ & $\mathbf{p}_{\mathrm{i}^{*} \mathbf{0}}^{\mathrm{e}^{\prime}}+\mathbf{p}^{\mathrm{e}^{\mathrm{s}}{ }^{*}{ }^{*} \mathbf{1}}$ & $\ldots \ldots \ldots$ & $\mathbf{p}_{\mathrm{i}^{*} \mathbf{0}}^{\mathrm{e}^{\prime}}+\mathbf{p}_{\mathrm{i}^{*} 1}^{\mathrm{e}^{\prime}}+\ldots+\mathbf{p}^{\mathrm{e}^{\prime}{ }^{*}{ }^{*}=1}$ \\
\hline
\end{tabular}

Note: Calculation of cumulative probabilities. Case of a married head.

Table 4. Cumulative probabilities of the number of dependents case of a unmarried household head

\begin{tabular}{|c|c|c|c|c|}
\hline Number of dependents $j$ & 0 & 1 & $\ldots \ldots$ & $\mathrm{n}$ \\
\hline $\mathbf{p}_{\mathrm{i}^{*} \mathrm{j} j}^{e_{j}}$ & $\mathbf{p}_{\mathrm{i}^{*} \mathbf{0}}^{\mathrm{e}}$ & $\mathbf{p}_{\mathrm{i}^{*} 1}^{e}$ & ....... & $\mathbf{p}_{\mathrm{i}^{\star} \mathrm{n}}^{\mathrm{e}}$ \\
\hline $\mathbf{P}_{\mathrm{i}^{*} \mathrm{j}}^{\mathrm{e}}$ & $\mathbf{p}_{\mathrm{i}^{*} 0}^{\mathrm{e}_{0}}$ & $\mathbf{p}_{\mathrm{i}^{*} 0}^{\mathrm{e}}+\mathbf{p}_{\mathrm{i}^{*} 1}^{\mathrm{e}}$ & $\ldots \ldots \ldots$ & $\mathbf{p}_{\mathrm{i}^{*} 0}^{\mathrm{e}}+\mathbf{p}_{\mathrm{i}^{*} 1}^{\mathrm{e}_{1}}+\ldots .+\mathbf{p}_{\mathrm{i}^{*} \mathrm{n}}^{\mathrm{e}}=1$ \\
\hline
\end{tabular}

Note: Calculation of cumulative probabilities. Case of an unmarried head.

Having calculated the cumulative probabilities associated with the number of dependents, generating a number of such individuals comes down to asking the computer to obtain a random number $\mathbf{X}$ and finding the value of $\mathbf{j}^{*}$ which satisfies the following condition:

$$
\begin{aligned}
& \boldsymbol{P}_{\left.i^{*} G^{*}-1\right)}^{e^{*}}<\boldsymbol{X} \leq \boldsymbol{P}_{i^{*} j^{*}}^{e^{*}} \text { If the marital status is «married» } \\
& \boldsymbol{P}_{i^{*}\left(j^{*}-1\right)}^{e^{*}}<\boldsymbol{X} \leq \boldsymbol{P}_{i^{*} j^{*}}^{e} \text { If the marital status is «unmarried» }
\end{aligned}
$$

Armed with these theoretical definitions, we can proceed to one or more simulations. It is the possibility of proceeding to more than one simulation that interests us in particular. For each simulation we obtain an estimate of the poverty threshold and an estimate of the poverty rate associated to this threshold. Allowing us to make a statistical analysis of the probability distribution of these variables. If a distribution law can be determined for each of the two variables, we will be able to establish a confidence interval for each with a desired level of confidence. With the use of simulation, we need no longer take several samples of observation: one sample will do.

\section{Application}

To start the simulation, we obtained a sample of 5374 observations. These observations were collected in a very large institutions that operate in Algeria and that employs more than 11000 agents. They are intent for example purpose only. Each observation is a triplet consisting of the marital status of the household head, the number of dependents and the household income. Table 5 shows a sample of the original data.

Table 5. Some of the original data

\begin{tabular}{ccc}
\hline number of dependents & Marital Status & Monthly Income \\
\hline & 1 & 27554.80 \\
6 & 1 & 31330.19 \\
5 & 1 & 36164.25 \\
5 & 1 & 29977.30 \\
1 & 1 & 33826.00 \\
3 & 1 & 29168.51 \\
1 & 1 & 27142.08 \\
1 & 1 & 33441.75 \\
2 & 1 & 29546.37 \\
2 & 1 & 34041.75 \\
5 & 1 & 33403.50 \\
1 & 1 & 33083.75 \\
2 & 1 & 26307.94 \\
6 & 1 & 33403.50 \\
1 & 0 & 35514.75 \\
1 & 1 & 27870.36 \\
2 & 1 & 32171.25 \\
2 & 1 & 30146.37 \\
3 & 1 & 34053.00 \\
10 & 1 & 23633.25 \\
3 & 1 & 33855.75 \\
\hline
\end{tabular}

Note: Marital status $=0$ for unmarried, 1 for married. 
Having obtained the original data, we start the process by classifying the observations according to the marital status. Once the data is divided into 2 categories, we need to group them by income class and marital status in order to achieve the tables for the $\mathbf{O}_{\mathrm{ij}}$ and the $\mathbf{O}^{\prime}{ }_{\mathrm{ij}}$ as defined by equations 1,2 and 3 . We chose to take a number of classes equal to 25 which ensures that the interclass interval is approximately 2000.00.

Tables 6 and 7 are the basis of the probabilities evaluation. First we calculate the probabilities of the income classes $\mathbf{p}_{\mathbf{i}}^{\mathbf{c}}$ according to equation 5. In table 8 are given the probabilities of the different income classes.

Table 6. Distribution of the $\mathbf{O}_{\text {ij }}^{\prime}$ for married household heads

\begin{tabular}{|c|c|c|c|c|c|c|c|c|c|c|c|c|c|c|}
\hline \multicolumn{2}{|c|}{ Class Limits } & \multicolumn{13}{|c|}{ Number of dependent individuals } \\
\hline lower & upper & 0 & 1 & 2 & 3 & 4 & 5 & 6 & 7 & 8 & 9 & 10 & 11 & total \\
\hline 5.50 & 2025.91 & 0 & 1 & 7 & 11 & 0 & 0 & 0 & 0 & 0 & 0 & 0 & 0 & 19 \\
\hline 2025.91 & 4046.32 & 0 & 0 & 0 & 0 & 7 & 2 & 1 & 0 & 0 & 0 & 0 & 0 & 10 \\
\hline 4046.32 & 6066.73 & 0 & 0 & 0 & 0 & 0 & 0 & 0 & 0 & 0 & 0 & 0 & 0 & 0 \\
\hline 6066.73 & 8087.15 & 0 & 0 & 0 & 0 & 0 & 0 & 0 & 0 & 0 & 0 & 0 & 0 & 0 \\
\hline 8087.15 & 10107.56 & 0 & 2 & 1 & 0 & 1 & 0 & 0 & 0 & 0 & 0 & 0 & 0 & 4 \\
\hline 10107.56 & 12127.97 & 0 & 26 & 1 & 3 & 1 & 1 & 0 & 0 & 0 & 0 & 0 & 0 & 32 \\
\hline 12127.97 & 14148.38 & 0 & 42 & 28 & 15 & 12 & 3 & 2 & 0 & 0 & 0 & 0 & 0 & 102 \\
\hline 14148.38 & 16168.79 & 0 & 25 & 71 & 86 & 50 & 25 & 2 & 2 & 0 & 0 & 0 & 0 & 261 \\
\hline 16168.79 & 18189.21 & 0 & 15 & 56 & 64 & 64 & 65 & 14 & 3 & 0 & 0 & 0 & 0 & 281 \\
\hline 18189.21 & 20209.62 & 0 & 19 & 52 & 78 & 73 & 39 & 11 & 2 & 1 & 0 & 0 & 0 & 275 \\
\hline 20209.62 & 22230.03 & 0 & 9 & 22 & 27 & 40 & 41 & 6 & 2 & 0 & 0 & 0 & 0 & 147 \\
\hline 22230.03 & 24250.44 & 0 & 14 & 32 & 34 & 16 & 18 & 5 & 1 & 0 & 0 & 0 & 0 & 120 \\
\hline 24250.44 & 26270.85 & 0 & 16 & 36 & 37 & 55 & 21 & 2 & 1 & 0 & 0 & 0 & 0 & 168 \\
\hline 26270.85 & 28291.26 & 0 & 28 & 78 & 67 & 47 & 40 & 16 & 2 & 0 & 0 & 0 & 0 & 278 \\
\hline 28291.26 & 30311.67 & 0 & 20 & 127 & 171 & 111 & 39 & 9 & 3 & 2 & 0 & 1 & 0 & 483 \\
\hline 30311.67 & 32332.09 & 0 & 48 & 88 & 142 & 224 & 120 & 22 & 5 & 1 & 0 & 0 & 0 & 650 \\
\hline 32332.09 & 34352.50 & 0 & 14 & 119 & 240 & 266 & 129 & 36 & 13 & 2 & 0 & 0 & 1 & 820 \\
\hline 34352.50 & 36372.91 & 0 & 22 & 48 & 91 & 147 & 166 & 91 & 20 & 6 & 0 & 0 & 0 & 591 \\
\hline 36372.91 & 38393.32 & 0 & 15 & 74 & 104 & 102 & 63 & 25 & 11 & 2 & 0 & 0 & 0 & 396 \\
\hline 38393.32 & 40413.73 & 0 & 7 & 24 & 86 & 91 & 88 & 27 & 7 & 0 & 0 & 0 & 0 & 330 \\
\hline 40413.73 & 42434.14 & 0 & 6 & 5 & 10 & 21 & 13 & 13 & 4 & 0 & 0 & 0 & 0 & 72 \\
\hline 42434.14 & 44454.55 & 0 & 4 & 10 & 7 & 2 & 2 & 6 & 0 & 0 & 0 & 0 & 0 & 31 \\
\hline 44454.55 & 46474.96 & 0 & 2 & 1 & 5 & 10 & 1 & 1 & 0 & 0 & 0 & 0 & 0 & 20 \\
\hline 46474.97 & 48495.38 & 0 & 0 & 2 & 2 & 5 & 3 & 0 & 0 & 0 & 0 & 0 & 0 & 12 \\
\hline 48495.38 & 50515.79 & 0 & 0 & 0 & 0 & 1 & 2 & 0 & 0 & 0 & 0 & 0 & 0 & 3 \\
\hline Total & & 0 & 335 & 882 & 1280 & 1346 & 881 & 289 & 76 & 14 & 0 & 1 & 1 & 5105 \\
\hline
\end{tabular}

Note: Grouping of the data by income class and number of dependents for the married household heads. 
Table 7. Distribution of the $\mathbf{O}_{\mathrm{ij}}$ for married household heads

\begin{tabular}{|c|c|c|c|c|c|c|c|c|c|c|c|}
\hline \multicolumn{2}{|c|}{ Class limits } & \multicolumn{10}{|c|}{ Number of dependent individuals } \\
\hline lower & upper & 0 & 1 & 2 & 3 & 4 & 5 & 6 & 7 & 8 & total \\
\hline 5.5 & 2025.912 & 0 & 0 & 11 & 3 & 0 & 0 & 0 & 0 & 0 & 14 \\
\hline 2025.912 & 4046.323 & 0 & 0 & 0 & 0 & 2 & 1 & 1 & 0 & 0 & 4 \\
\hline 4046.323 & 6066.735 & 0 & 0 & 0 & 0 & 0 & 0 & 0 & 0 & 0 & 0 \\
\hline 6066.735 & 8087.146 & 0 & 0 & 0 & 0 & 0 & 0 & 0 & 0 & 0 & 0 \\
\hline 8087.146 & 10107.56 & 0 & 0 & 0 & 0 & 0 & 0 & 0 & 0 & 0 & 0 \\
\hline 10107.56 & 12127.97 & 0 & 0 & 1 & 0 & 0 & 0 & 0 & 0 & 0 & 1 \\
\hline 12127.97 & 14148.38 & 0 & 2 & 2 & 1 & 2 & 0 & 0 & 0 & 0 & 7 \\
\hline 14148.38 & 16168.79 & 0 & 0 & 16 & 8 & 1 & 0 & 0 & 0 & 0 & 25 \\
\hline 16168.79 & 18189.21 & 0 & 0 & 3 & 2 & 2 & 1 & 0 & 0 & 0 & 8 \\
\hline 18189.21 & 20209.62 & 0 & 0 & 3 & 1 & 0 & 0 & 0 & 0 & 0 & 4 \\
\hline 20209.62 & 22230.03 & 0 & 1 & 2 & 0 & 0 & 1 & 0 & 0 & 0 & 4 \\
\hline 22230.03 & 24250.44 & 0 & 0 & 6 & 0 & 0 & 0 & 0 & 0 & 0 & 6 \\
\hline 24250.44 & 26270.85 & 0 & 1 & 7 & 1 & 2 & 0 & 0 & 0 & 0 & 11 \\
\hline 26270.85 & 28291.26 & 0 & 0 & 9 & 4 & 0 & 1 & 0 & 0 & 0 & 14 \\
\hline 28291.26 & 30311.67 & 0 & 0 & 17 & 12 & 0 & 1 & 0 & 0 & 0 & 30 \\
\hline 30311.67 & 32332.09 & 0 & 0 & 24 & 8 & 2 & 1 & 0 & 0 & 0 & 35 \\
\hline 32332.09 & 34352.5 & 0 & 0 & 25 & 19 & 3 & 4 & 1 & 1 & 0 & 53 \\
\hline 34352.5 & 36372.91 & 0 & 2 & 9 & 7 & 3 & 3 & 0 & 1 & 1 & 26 \\
\hline 36372.91 & 38393.32 & 0 & 0 & 7 & 5 & 3 & 2 & 0 & 0 & 0 & 17 \\
\hline 38393.32 & 40413.73 & 0 & 1 & 1 & 3 & 0 & 1 & 0 & 0 & 0 & 6 \\
\hline 40413.73 & 42434.14 & 0 & 0 & 1 & 1 & 0 & 0 & 0 & 0 & 0 & 2 \\
\hline 42434.14 & 44454.55 & 0 & 0 & 1 & 0 & 0 & 0 & 0 & 0 & 0 & 1 \\
\hline 44454.55 & 46474.96 & 0 & 0 & 0 & 0 & 1 & 0 & 0 & 0 & 0 & 1 \\
\hline 46474.97 & 48495.38 & 0 & 0 & 0 & 0 & 0 & 0 & 0 & 0 & 0 & 0 \\
\hline 48495.38 & 50515.79 & 0 & 0 & 0 & 0 & 0 & 0 & 0 & 0 & 0 & 0 \\
\hline Total & & 0 & 7 & 145 & 75 & 21 & 16 & 2 & 2 & 1 & 269 \\
\hline
\end{tabular}

Note: Grouping by income class and number of dependents for the unmarried household heads $\mathbf{j}_{\mathbf{j}}$.

Table 8 . Probability of classes

\begin{tabular}{ccc}
\hline & Class limits & \multicolumn{2}{c}{ Class probabilities } \\
\hline lower & upper & $6.14 \mathrm{E}-03$ \\
2025.912 & 2025.912 & $2.61 \mathrm{E}-03$ \\
4046.323 & 4046.323 & 0 \\
6066.735 & 6066.735 & 0 \\
8087.146 & 8087.146 & $7.44 \mathrm{E}-04$ \\
10107.56 & 10107.56 & $6.14 \mathrm{E}-03$ \\
12127.97 & 12127.97 & $2.03 \mathrm{E}-02$ \\
14148.38 & 14148.38 & $5.36 \mathrm{E}-02$ \\
16168.79 & 16168.79 & $5.36 \mathrm{E}-02$ \\
18189.21 & 18189.21 & $5.17 \mathrm{E}-02$ \\
20209.62 & 20209.62 & $2.81 \mathrm{E}-02$ \\
22230.03 & 22230.03 & $2.34 \mathrm{E}-02$ \\
24250.44 & 24250.44 & $3.41 \mathrm{E}-02$ \\
26270.85 & 26270.85 & $5.38 \mathrm{E}-02$ \\
28291.26 & 28291.26 & $9.53 \mathrm{E}-02$ \\
30311.67 & 30311.67 & 0.1276517 \\
32332.09 & 32332.09 & 0.1622628 \\
34352.5 & 34352.5 & 0.1148121 \\
36372.91 & 36372.91 & $7.69 \mathrm{E}-02$ \\
38393.32 & 38393.32 & $6.27 \mathrm{E}-02$ \\
40413.73 & 40413.73 & $1.36 \mathrm{E}-02$ \\
42434.14 & 42434.14 & $5.95 \mathrm{E}-03$ \\
44454.55 & 44454.55 & $3.91 \mathrm{E}-03$ \\
46474.97 & 46474.96 & $2.23 \mathrm{E}-03$ \\
48495.38 & 48495.38 & $5.58 \mathrm{E}-04$ \\
\hline
\end{tabular}

Note: Probability that a given income falls in an income class. 
Using equations 6 and 7, we evaluate the estimators of the marginal probabilities of the marital status. This is done in table 9 .

Table 9. Probabilities $\mathbf{P}_{\mathbf{i}}^{\mathbf{s}}$ and $\mathbf{P}^{\mathbf{s}}{ }_{\mathbf{i}}$

\begin{tabular}{|c|c|c|c|}
\hline \multicolumn{2}{|c|}{ Class Limits } & \multicolumn{2}{|c|}{ Marital status Probability } \\
\hline lower & upper & unmarried & married \\
\hline 5.5 & 2025.912 & 0.4242424 & 0.5757576 \\
\hline 2025.912 & 4046.323 & 0.2857143 & 0.7142857 \\
\hline 4046.323 & 6066.735 & 0 & 0 \\
\hline 6066.735 & 8087.146 & 0 & 0 \\
\hline 8087.146 & 10107.56 & 0 & 1 \\
\hline 10107.56 & 12127.97 & 3.03E-02 & 0.969697 \\
\hline 12127.97 & 14148.38 & $6.42 \mathrm{E}-02$ & 0.9357798 \\
\hline 14148.38 & 16168.79 & $8.68 \mathrm{E}-02$ & 0.9131944 \\
\hline 16168.79 & 18189.21 & $2.78 \mathrm{E}-02$ & 0.9722222 \\
\hline 18189.21 & 20209.62 & $1.44 \mathrm{E}-02$ & 0.9856115 \\
\hline 20209.62 & 22230.03 & $2.65 \mathrm{E}-02$ & 0.9735099 \\
\hline 22230.03 & 24250.44 & $4.76 \mathrm{E}-02$ & 0.952381 \\
\hline 24250.44 & 26270.85 & $6.01 \mathrm{E}-02$ & 0.9398907 \\
\hline 26270.85 & 28291.26 & 4.84E-02 & 0.9515571 \\
\hline 28291.26 & 30311.67 & $5.86 \mathrm{E}-02$ & 0.9414063 \\
\hline 30311.67 & 32332.09 & $5.10 \mathrm{E}-02$ & 0.9489796 \\
\hline 32332.09 & 34352.5 & $6.08 \mathrm{E}-02$ & 0.9392202 \\
\hline 34352.5 & 36372.91 & 4.21E-02 & 0.9578606 \\
\hline 36372.91 & 38393.32 & 4.12E-02 & 0.9588377 \\
\hline 38393.32 & 40413.73 & $1.78 \mathrm{E}-02$ & 0.9821959 \\
\hline 40413.73 & 42434.14 & $2.74 \mathrm{E}-02$ & 0.9726027 \\
\hline 42434.14 & 44454.55 & 0.03125 & 0.96875 \\
\hline 44454.55 & 46474.96 & 4.76E-02 & 0.952381 \\
\hline 46474.97 & 48495.38 & 0 & 1 \\
\hline 48495.38 & 50515.79 & 0 & 1 \\
\hline
\end{tabular}

Note: Marital status probabilities by income class.

The final step in the derivation of the probability estimates is to evaluate the marginal probability estimates of the number of dependent people knowing the class of income and the marital status of the household head in conformity with to equations 8 and 9 . Table 10 gives the probability distribution of the number of dependents per household whose heads are unmarried, while table 11 gives the same for married household heads. 
Table 10. Probability $\mathbf{p}^{\mathbf{e}} \mathbf{i j}_{\mathbf{j}}$

\begin{tabular}{|c|c|c|c|c|c|c|c|c|c|c|}
\hline \multicolumn{2}{|c|}{ Class limits } & \multicolumn{9}{|c|}{ Number of dependent individuals } \\
\hline lower & upper & 0 & 1 & 2 & 3 & 4 & 5 & 6 & 7 & 8 \\
\hline 5.5 & 2025.91 & 0.000 & 0.000 & 0.786 & 0.214 & 0.000 & 0.000 & 0.000 & 0.000 & 0.000 \\
\hline 2025.91 & 4046.32 & 0.000 & 0.000 & 0.000 & 0.000 & 0.500 & 0.250 & 0.250 & 0.000 & 0.000 \\
\hline 4046.32 & 6066.73 & 0.000 & 0.000 & 0.000 & 0.000 & 0.000 & 0.000 & 0.000 & 0.000 & 0.000 \\
\hline 6066.73 & 8087.14 & 0.000 & 0.000 & 0.000 & 0.000 & 0.000 & 0.000 & 0.000 & 0.000 & 0.000 \\
\hline 8087.14 & 10107.55 & 0.000 & 0.000 & 0.000 & 0.000 & 0.000 & 0.000 & 0.000 & 0.000 & 0.000 \\
\hline 10107.5 & 12127.97 & 0.000 & 0.000 & 1.000 & 0.000 & 0.000 & 0.000 & 0.000 & 0.000 & 0.000 \\
\hline 12127.97 & 14148.38 & 0.000 & 0.286 & 0.286 & 0.143 & 0.286 & 0.000 & 0.000 & 0.000 & 0.000 \\
\hline 14148.38 & 16168.79 & 0.000 & 0.000 & 0.640 & 0.320 & 0.040 & 0.000 & 0.000 & 0.000 & 0.000 \\
\hline 16168.79 & 18189.20 & 0.000 & 0.000 & 0.375 & 0.250 & 0.250 & 0.125 & 0.000 & 0.000 & 0.000 \\
\hline 18189.20 & 20209.61 & 0.000 & 0.000 & 0.750 & 0.250 & 0.000 & 0.000 & 0.000 & 0.000 & 0.000 \\
\hline 20209.62 & 22230.02 & 0.000 & 0.250 & 0.500 & 0.000 & 0.000 & 0.250 & 0.000 & 0.000 & 0.000 \\
\hline 22230.03 & 24250.44 & 0.000 & 0.000 & 1.000 & 0.000 & 0.000 & 0.000 & 0.000 & 0.000 & 0.000 \\
\hline 24250.44 & 26270.85 & 0.000 & 0.091 & 0.636 & 0.091 & 0.182 & 0.000 & 0.000 & 0.000 & 0.000 \\
\hline 26270.85 & 28291.26 & 0.000 & 0.000 & 0.643 & 0.286 & 0.000 & 0.071 & 0.000 & 0.000 & 0.000 \\
\hline 28291.26 & 30311.67 & 0.000 & 0.000 & 0.567 & 0.400 & 0.000 & 0.033 & 0.000 & 0.000 & 0.000 \\
\hline 30311.67 & 32332.09 & 0.000 & 0.000 & 0.686 & 0.229 & 0.057 & 0.029 & 0.000 & 0.000 & 0.000 \\
\hline 32332.09 & 34352.5 & 0.000 & 0.000 & 0.472 & 0.358 & 0.057 & 0.075 & 0.019 & 0.019 & 0.000 \\
\hline 34352.5 & 36372.91 & 0.000 & 0.077 & 0.346 & 0.269 & 0.115 & 0.115 & 0.000 & 0.038 & 0.038 \\
\hline 36372.91 & 38393.32 & 0.000 & 0.000 & 0.412 & 0.294 & 0.176 & 0.118 & 0.000 & 0.000 & 0.000 \\
\hline 38393.32 & 40413.73 & 0.000 & 0.167 & 0.167 & 0.500 & 0.000 & 0.167 & 0.000 & 0.000 & 0.000 \\
\hline 40413.73 & 42434.14 & 0.000 & 0.000 & 0.500 & 0.500 & 0.000 & 0.000 & 0.000 & 0.000 & 0.000 \\
\hline 42434.14 & 44454.55 & 0.000 & 0.000 & 1.000 & 0.000 & 0.000 & 0.000 & 0.000 & 0.000 & 0.000 \\
\hline 44454.55 & 46474.97 & 0.000 & 0.000 & 0.000 & 0.000 & 1.000 & 0.000 & 0.000 & 0.000 & 0.000 \\
\hline 46474.97 & 48495.38 & 0.000 & 0.000 & 0.000 & 0.000 & 0.000 & 0.000 & 0.000 & 0.000 & 0.000 \\
\hline 48495.38 & 50515.79 & 0.000 & 0.000 & 0.000 & 0.000 & 0.000 & 0.000 & 0.000 & 0.000 & 0.000 \\
\hline
\end{tabular}

Note: Probabilities of the number of dependents per class for the non married household heads.

Table 11. Calculation of $\mathbf{p}^{\mathbf{e}^{\mathbf{e}}}{ }_{\mathbf{i j}}$

\begin{tabular}{|c|c|c|c|c|c|c|c|c|c|c|c|c|c|}
\hline \multicolumn{2}{|c|}{ Class Limits } & \multicolumn{12}{|c|}{ Number of dependent individuals } \\
\hline lower & upper & 0 & 1 & 2 & 3 & 4 & 5 & 6 & 7 & 8 & 9 & 10 & 11 \\
\hline 5.5 & 2025.91 & 0 & $5.26 \mathrm{E}-02$ & 0.36842 & 0.579 & 0 & 0 & 0 & 0 & 0 & 0 & 0 & 0 \\
\hline 2025.91 & 4046.32 & 0 & 0 & 0 & 0 & 0.7 & 0.2 & 0.1 & 0 & 0 & 0 & 0 & 0 \\
\hline 4046.32 & 6066.73 & 0 & 0 & 0 & 0 & 0 & 0 & 0 & 0 & 0 & 0 & 0 & 0 \\
\hline 6066.73 & 8087.14 & 0 & 0 & 0 & 0 & 0 & 0 & 0 & 0 & 0 & 0 & 0 & 0 \\
\hline 8087.14 & 10107.56 & 0 & 0.5 & 0.25 & 0 & 0.25 & 0 & 0 & 0 & 0 & 0 & 0 & 0 \\
\hline 10107.56 & 12127.97 & 0 & 0.8125 & 0.03125 & 0.094 & 0.03125 & 0.03125 & 0 & 0 & 0 & 0 & 0 & 0 \\
\hline 12127.97 & 14148.38 & 0 & 0.41176 & 0.27451 & 0.147 & 0.11765 & $2.94 \mathrm{E}-02$ & $1.96 \mathrm{E}-02$ & 0 & 0 & 0 & 0 & 0 \\
\hline 14148.38 & 16168.79 & 0 & $9.51 \mathrm{E}-02$ & 0.26996 & 0.327 & 0.19772 & $9.51 \mathrm{E}-02$ & 7.60E-03 & $7.60 \mathrm{E}-03$ & 0 & 0 & 0 & 0 \\
\hline 16168.79 & 18189.21 & 0 & $5.36 \mathrm{E}-02$ & 0.20357 & 0.229 & 0.22143 & 0.23214 & 0.05 & $1.07 \mathrm{E}-02$ & 0 & 0 & 0 & 0 \\
\hline 18189.21 & 20209.62 & 0 & $6.93 \mathrm{E}-02$ & 0.18613 & 0.285 & 0.26642 & 0.14234 & $4.01 \mathrm{E}-02$ & $7.30 \mathrm{E}-03$ & $3.65 \mathrm{E}-03$ & 0 & 0 & 0 \\
\hline 20209.62 & 22230.03 & 0 & $6.12 \mathrm{E}-02$ & 0.14966 & 0.184 & 0.27211 & 0.27891 & $4.08 \mathrm{E}-02$ & $1.36 \mathrm{E}-02$ & 0 & 0 & 0 & 0 \\
\hline 22230.03 & 24250.44 & 0 & 0.11667 & 0.26667 & 0.283 & 0.13333 & 0.15 & $4.17 \mathrm{E}-02$ & $8.33 \mathrm{E}-03$ & 0 & 0 & 0 & 0 \\
\hline 24250.44 & 26270.85 & 0 & $9.30 \mathrm{E}-02$ & 0.2093 & 0.221 & 0.33721 & 0.12209 & $1.16 \mathrm{E}-02$ & $5.81 \mathrm{E}-03$ & 0 & 0 & 0 & 0 \\
\hline 26270.85 & 28291.26 & 0 & 0.10182 & 0.28727 & 0.24 & 0.16 & 0.14545 & $5.82 \mathrm{E}-02$ & $7.27 \mathrm{E}-03$ & 0 & 0 & 0 & 0 \\
\hline 28291.26 & 30311.67 & 0 & $4.15 \mathrm{E}-02$ & 0.26141 & 0.355 & 0.23029 & $8.09 \mathrm{E}-02$ & 0.018672 & $6.22 \mathrm{E}-03$ & $4.15 \mathrm{E}-03$ & 0 & $2.07 \mathrm{E}-03$ & 0 \\
\hline 30311.67 & 32332.08 & 0 & 7.37E-02 & 0.13518 & 0.218 & 0.34409 & 0.18433 & $3.53 \mathrm{E}-02$ & $7.68 \mathrm{E}-03$ & $1.54 \mathrm{E}-03$ & 0 & 0 & 0 \\
\hline 32332.08 & 34352.5 & 0 & $1.71 \mathrm{E}-02$ & 0.1453 & 0.293 & 0.32479 & 0.15751 & $4.27 \mathrm{E}-02$ & $1.59 \mathrm{E}-02$ & $2.44 \mathrm{E}-03$ & 0 & 0 & $1.22 \mathrm{E}-03$ \\
\hline 34352.5 & 36372.91 & 0 & $3.72 \mathrm{E}-02$ & $8.12 \mathrm{E}-02$ & 0.154 & 0.24873 & 0.28088 & 0.153976 & $3.38 \mathrm{E}-02$ & $1.02 \mathrm{E}-02$ & 0 & 0 & 0 \\
\hline 36372.91 & 38393.32 & 0 & $3.79 \mathrm{E}-02$ & 0.18687 & 0.263 & 0.25758 & 0.15909 & $6.31 \mathrm{E}-02$ & $2.78 \mathrm{E}-02$ & $5.05 \mathrm{E}-03$ & 0 & 0 & 0 \\
\hline 38393.32 & 40413.73 & 0 & $2.11 \mathrm{E}-02$ & $7.25 \mathrm{E}-02$ & 0.263 & 0.27492 & 0.26586 & 0.081571 & $2.11 \mathrm{E}-02$ & 0 & 0 & 0 & 0 \\
\hline 40413.73 & 42434.14 & 0 & $8.45 \mathrm{E}-02$ & $7.04 \mathrm{E}-02$ & 0.127 & 0.29577 & 0.1831 & 0.183099 & $5.63 \mathrm{E}-02$ & 0 & 0 & 0 & 0 \\
\hline 42434.14 & 44454.55 & 0 & 0.12903 & 0.32258 & 0.226 & $6.45 \mathrm{E}-02$ & $6.45 \mathrm{E}-02$ & 0.193548 & 0 & 0 & 0 & 0 & 0 \\
\hline 44454.55 & 46474.97 & 0 & 0.1 & 0.05 & 0.25 & 0.5 & 0.05 & 0.05 & 0 & 0 & 0 & 0 & 0 \\
\hline 46474.97 & 48495.38 & 0 & 0 & 0.16667 & 0.167 & 0.41667 & 0.25 & 0 & 0 & 0 & 0 & 0 & 0 \\
\hline 48495.38 & 50515.78 & 0 & 0 & 0 & 0 & 0.33333 & 0.66667 & 0 & 0 & 0 & 0 & 0 & 0 \\
\hline
\end{tabular}

Note: Number of dependents probabilities per income class for the married household heads. 
Using the different estimators of the probabilities presented in Tables 8 to 11, we can generate a sample of virtual observations in accordance with the laws of probability distribution that underlie the original sample of 5374 observations insight of which is given in Table 5 . We chose to include in this computer-generated sample 5000 observations each consisting of the triplet (marital status, number of dependents, income).

for the sake of the application, we use the Oxford scale to assess the consumption units. The household head counts as one unit, the spouse if any accounts for 0.7 units. Each of the other dependents in the household account for 0.5 units of consumption. The poverty line is set at $60 \%$ of the median income. It should be noted that the simulation does not impose any assumption related to the consumption units or the definition of the poverty line. Any other hypothesis can be considered.

\section{Simulation Algorithm}

1. For each household head in the simulation (there are 5000)

Generate income class;

Generate income in this class;

Generate marital status;

Generate the number of dependents;

Calculate the number of consumer units according to the Oxford scale;

Calculate the income per consumption unit.

2. After completing the generation process above for all the individuals, calculate the median income per consumption unit. The poverty line is equal to $60 \%$ of the median.

3. For each pair (consumption units, income), compare the income poverty line calculated in step 2 above. If the income per consumption unit is below the poverty line, add the number of consumption units to the total of poor people.

4. The poverty rate is the ratio of the number of poor people to the total number of consumption units in the sample.

Table 12. Sample of simulated observations

\begin{tabular}{lll}
\hline Marital Status & Number of dependents & Income \\
\hline 0 & 2 & 24535.97 \\
1 & 3 & 31209.5 \\
1 & 6 & 35876.65 \\
1 & 3 & 33630.55 \\
1 & 1 & 23520.31 \\
1 & 4 & 15906.58 \\
1 & 3 & 30220.16 \\
0 & 2 & 16450.08 \\
1 & 4 & 29688.18 \\
1 & 4 & 31402.74 \\
1 & 2 & 26605.43 \\
1 & 5 & 27768.1 \\
\hline
\end{tabular}

Note: Some of the data generated by the simulation program.

Now that we are able to do a simulation, it is easy to assess the threshold and the poverty rate associated with the values generated by the simulation. However, there is no reason to perform only a single simulation. In fact, we can do more in order to generate multiple values for the threshold and the poverty rate. This generation allows us to do a statistical analysis of these two variables. Do the threshold and the poverty rate follow a particular distribution law? With this in mind we conducted 500 simulation run, each requiring the realization of 5000 observations. This collection of simulations resulted in a sample of 500 poverty thresholds and poverty rates insight of which is given in the table 13, while table 14 summarizes some of the statistics relative to the threshold and the poverty rate. 
Table 13. Computer generated thresholds and rates sample

\begin{tabular}{ll}
\hline Threshold & Rate (\%) \\
\hline 5157.80 & 11.55 \\
5092.47 & 11.51 \\
5130.99 & 11.26 \\
5156.49 & 10.91 \\
5121.88 & 11.19 \\
5134.68 & 12.12 \\
5162.19 & 11.03 \\
5112.28 & 11.57 \\
5113.53 & 11.63 \\
5146.33 & 11.77 \\
5122.21 & 12.08 \\
5102.48 & 11.46 \\
5071.57 & 12.21 \\
5158.72 & 10.91 \\
\hline
\end{tabular}

\section{Statistical Analysis}

The 500 simulations gave birth to some statistics. The ones needed for the analysis that is to follow are summarized in table 14 .

Table 14. Statistics of the threshold and rate

\begin{tabular}{lll}
\hline & Origin of Statistics & \\
\hline Statistics & Threshold & Poverty Rate \\
Max & 5195.903 & 12.89 \\
Min & 5061.599 & 10.3 \\
Average & 5125.401746 & 11.56904 \\
Stand. Dev & 24.21691016 & 0.429249565 \\
Variance & 585.2856749 & 0.1839 \\
Number of observations & 500 & 500 \\
Grouping interval with & 6.715185547 & 0.1295 \\
\hline
\end{tabular}

Note: Statistics collected after running 500 simulations.

We use the test of the goodness of fit which is based on the chi-squared distribution. If we denote by $\mathbf{f}_{\mathbf{i}}$ the ith observed frequency of a random variable $\mathbf{X}$, and by $\mathbf{e}_{\mathbf{i}}$ the corresponding expected value, then the new variable $\chi_{\mathbf{c}}^{2}$ (chi squared calculated) $=\left(\mathbf{f}_{\mathbf{i}}-\mathbf{e}_{\mathbf{i}}\right)^{2} / \mathbf{e}_{\mathbf{i}}$ follows the chi square distribution. $\mathbf{e}_{\mathbf{i}}$ represent the expected values if the variable $\mathbf{X}$ under study (the threshold or the poverty rate) is following a definite law. We start from the null hypothesis that the variable $\mathbf{X}$ under consideration follows the normal distribution and we verify if indeed the sample data support or refute this hypothesis. The value of the $\chi^{2}{ }_{c}$ is compared to $\chi^{2}{ }_{t}$ whose value is the theoretical value of a random variable following the chi square distribution. All calculations are given in tables 15 and 16 . We suggest to the reader Lapin L.L. (1973).

\subsection{Poverty Threshold Statistical Analysis}

The chi squared value calculated in Table 15 is 26.6540752 and the tabulated chi squared for 14 degrees of freedom is 26.873 . For a $2 \%$ risk, thus, we cannot reject the hypothesis of normality of the threshold distribution. Following this, the distribution of the threshold can be completely described by the normal distribution with an expected value equal to 5125.401753 and a variance of 586.4585921 . 
Table 15. Calculation of the goodness of fit test for the threshold

\begin{tabular}{|c|c|c|c|c|c|c|c|c|c|c|c|c|}
\hline $\begin{array}{l}\text { Class } \\
\text { limit }\end{array}$ & Lower & $\begin{array}{l}\text { Class } \\
\text { Limit }\end{array}$ & Upper & $f_{i}$ & $f_{i}$ & $\begin{array}{ll}\text { prob upper } \\
\text { limit }\end{array}$ & $\begin{array}{l}\text { Interval } \\
\text { prob }\end{array}$ & $\mathrm{e}_{\mathrm{i}}$ & $e_{i}$ & $\left(\mathrm{f}_{\mathrm{i}}-\mathrm{e}_{\mathrm{i}}\right)$ & $\left(f_{i}-e_{i}\right)^{2}$ & $\left(\mathrm{f}_{\mathrm{i}}-\mathrm{e}_{\mathrm{i}}\right)^{2} / \mathrm{e}_{\mathrm{i}}$ \\
\hline 0 & & 5061.60 & & 0 & 9 & 0.0042 & 0.00421 & 2.1057 & 9.3803 & -0.3803 & 0.1447 & 0.0154 \\
\hline 5061.60 & & 5068.31 & & 4 & & 0.0092 & 0.00499 & 2.4959 & & & & \\
\hline 5068.31 & & 5075.03 & & 5 & & 0.0188 & 0.00956 & 4.7787 & & & & \\
\hline 5075.03 & & 5081.74 & & 8 & & 0.0357 & 0.01695 & 8.4764 & & -0.4764 & 0.2270 & 0.0268 \\
\hline 5081.74 & & 5088.46 & & 12 & & 0.0636 & 0.02786 & 13.9294 & & -1.9294 & 3.7225 & 0.2672 \\
\hline 5088.46 & & 5095.18 & & 19 & & 0.1060 & 0.04241 & 21.2064 & & -2.2064 & 4.8684 & 0.2296 \\
\hline 5095.18 & & 5101.89 & & 30 & & 0.1658 & 0.05982 & 29.9104 & & 0.0896 & 0.0080 & 0.0003 \\
\hline 5101.89 & & 5108.61 & & 36 & & 0.2440 & 0.07817 & 39.0836 & & -3.0836 & 9.5086 & 0.2433 \\
\hline 5108.61 & & 5115.32 & & 75 & & 0.3386 & 0.09463 & 47.3137 & & 27.6863 & 766.5327 & 16.2011 \\
\hline 5115.32 & & 5122.04 & & 46 & & 0.4447 & 0.10613 & 53.0638 & & -7.0638 & 49.8972 & 0.9403 \\
\hline 5122.04 & & 5128.75 & & 49 & & 0.5550 & 0.11027 & 55.1353 & & -6.1353 & 37.6419 & 0.6827 \\
\hline 5128.75 & & 5135.47 & & 57 & & 0.6611 & 0.10615 & 53.0739 & & 3.9261 & 15.4142 & 0.2904 \\
\hline 5135.47 & & 5142.18 & & 36 & & 0.7558 & 0.09466 & 47.3317 & & -11.3317 & 128.4074 & 2.7129 \\
\hline 5142.18 & & 5148.90 & & 37 & & 0.8340 & 0.07821 & 39.1059 & & -2.1059 & 4.4350 & 0.1134 \\
\hline 5148.90 & & 5155.61 & & 29 & & 0.8939 & 0.05987 & 29.9332 & & -0.9332 & 0.8708 & 0.0291 \\
\hline 5155.61 & & 5162.33 & & 23 & & 0.9363 & 0.04245 & 21.2266 & & 1.7734 & 3.1448 & 0.1482 \\
\hline 5162.33 & & 5169.04 & & 13 & & 0.9642 & 0.02789 & 13.9453 & & -0.9453 & 0.8936 & 0.0641 \\
\hline 5169.04 & & 5175.76 & & 7 & & 0.9812 & 0.01698 & 8.4878 & & -1.4878 & 2.2134 & 0.2608 \\
\hline 5175.76 & & 5182.47 & & 10 & 14 & 0.9908 & 0.00957 & 4.7860 & 9.3962 & 4.6038 & 21.1949 & 4.4285 \\
\hline 5182.47 & & 5189.19 & & 1 & & 0.9958 & 0.00500 & 2.5002 & & & & \\
\hline 5189.19 & & 25000 & & 3 & & 1.0000 & 0.00422 & 2.1100 & & & & \\
\hline total & & & & 500 & & & & 500 & & & & 26.6540752 \\
\hline
\end{tabular}

Note: Required computations to evaluate the calculated chi squared value $\chi_{\mathrm{c}}^{2}$ for the threshold.

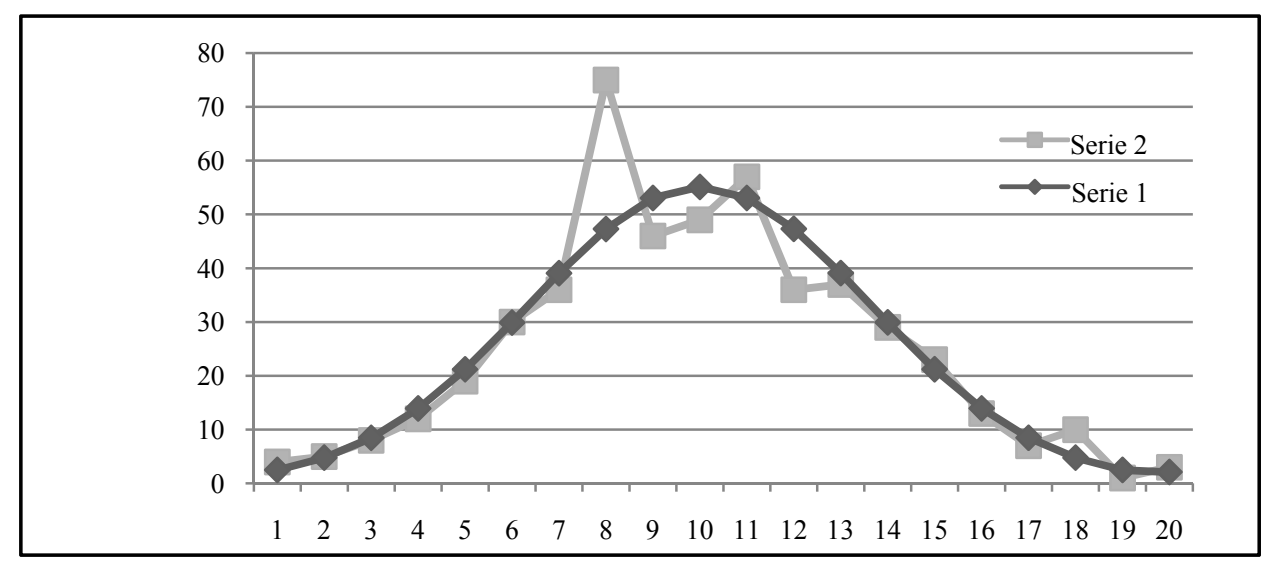

Figure 1. Distribution of the poverty threshold and normal distribution

Description: Serie 1: the expected values of the threshold under the normal distribution eij. Serie 2 their actual observed values oij.

If the assumption of the normal distribution for the threshold must be accepted, then we can calculate a confidence interval. Let's assume that the desired degree of confidence is $\mathrm{c}$ with $0 \leq \mathrm{c} \leq 100 \%$. $\alpha$, the risk is 1 -c, and therefore $0 \leq \alpha \leq 100 \%$. In accordance with the desired degree of confidence, we get $\mathbf{z}_{1-\alpha / 2}$ from the table of the standard normal distribution. The confidence interval for the poverty threshold would be:

$$
\text { Average threshold } \pm \mathbf{z}_{\mathbf{1}-\boldsymbol{\alpha} / \mathbf{2}} * \text { standard deviation of the threshold }
$$

Thus, for a confidence level of $95 \%, \mathbf{z}_{1-\alpha / 2}=1.96$. So we can estimate the $95 \%$ confidence interval for the threshold rate: $5125.401753 \pm 1.96 * 24.21690715=5125.401753 \pm 47.465138$.

That is confidence interval runs from 5077.93662 to 5172.86689 .

\subsection{Poverty Rate Statistical Analysis}

The Chi squared value calculated in Table 16 being 8.8316, and the tabulated chi squared for 13 degrees of freedom being 22.362 . For a risk of $5 \%$, we cannot reject the assumption of normality of the poverty rate distribution. Thus, the distribution of the poverty rate can be completely described by the normal distribution with an expected value equal to 0.1843 and a variance of 11.5690 . 
Table 16. Calculation of the goodness of fit test for the rate

\begin{tabular}{|c|c|c|c|c|c|c|c|c|c|}
\hline Lower limit & Upper Limit & $f_{i}$ & $f_{i}$ Upper lim probability & Interval probability & $e_{i}$ & $e_{i}$ & $\mathrm{f}_{\mathrm{i}}-\mathrm{e}_{\mathrm{i}}$ & $\left(f_{i}-e_{i}\right)^{2}$ & $\left(\mathrm{f}_{\mathrm{i}}-\mathrm{O}_{\mathrm{i}}\right)^{2} / \mathrm{e}_{\mathrm{i}}$ \\
\hline 0 & 10.3 & 0 & 70.0016 & 0.0016 & 0.77809 & 10.0583 & -3.0583 & 9.3532 & 0.9299 \\
\hline 10.30 & 10.43 & 3 & 0.0040 & 0.0024 & 1.2062 & & & & \\
\hline 10.43 & 10.56 & 3 & 0.0093 & 0.0053 & 2.6709 & & & & \\
\hline 10.56 & 10.69 & 1 & 0.0201 & 0.0108 & 5.4031 & & & & \\
\hline 10.69 & 10.82 & 10 & 0.0401 & 0.0200 & 9.9861 & & 0.0139 & 0.0002 & 0.0000 \\
\hline 10.82 & 10.95 & 17 & 0.0738 & 0.0337 & 16.8621 & & 0.1379 & 0.0190 & 0.0011 \\
\hline 10.95 & 11.08 & 24 & 0.1258 & 0.0520 & 26.0135 & & -2.0135 & 4.0540 & 0.1558 \\
\hline 11.08 & 11.21 & 33 & 0.1992 & 0.0733 & 36.6651 & & -3.6651 & 13.4327 & 0.3664 \\
\hline 11.21 & 11.34 & 59 & 0.2936 & 0.0944 & 47.2146 & & 11.7854 & 138.8955 & 2.9418 \\
\hline 11.34 & 11.47 & 59 & 0.4047 & 0.1111 & 55.5483 & & 3.4517 & 11.9143 & 0.2145 \\
\hline 11.47 & 11.60 & 67 & 0.5241 & 0.1194 & 59.7084 & & 7.2916 & 53.1670 & 0.8904 \\
\hline 11.60 & 11.72 & 52 & 0.6414 & 0.1173 & 58.6370 & & -6.6370 & 44.0495 & 0.7512 \\
\hline 11.72 & 11.85 & 47 & 0.7466 & 0.1052 & 52.6112 & & -5.6112 & 31.4858 & 0.5985 \\
\hline 11.85 & 11.98 & 38 & 0.8329 & 0.0863 & 43.1277 & & -5.1277 & 26.2928 & 0.6097 \\
\hline 11.98 & 12.11 & 30 & 0.8975 & 0.0646 & 32.3001 & & -2.3001 & 5.2902 & 0.1638 \\
\hline 12.11 & 12.24 & 26 & 0.9417 & 0.0442 & 22.1014 & & 3.8986 & 15.1990 & 0.6877 \\
\hline 12.24 & 12.37 & 15 & 0.9693 & 0.0276 & 13.8167 & & 1.1833 & 1.4002 & 0.1013 \\
\hline 12.37 & 12.50 & 7 & 0.9851 & 0.0158 & 7.8915 & & -0.8915 & 0.7947 & 0.1007 \\
\hline 12.50 & 12.63 & 7 & 90.9933 & 0.0082 & 4.1179 & 7.4582 & 1.5418 & 2.3772 & 0.3187 \\
\hline 12.63 & 12.76 & 1 & 0.9972 & 0.0039 & 1.9632 & & & & \\
\hline 12.76 & 12.89 & 1 & 0.9990 & 0.0017 & 0.8551 & & & & \\
\hline 12.89 & $\infty$ & 0 & 1.0000 & 0.0010 & 0.5221 & & & & \\
\hline total & & 500 & & 1.0000 & 500 & & & & 8.8316 \\
\hline
\end{tabular}

Note: Required computations to evaluate the calculated chi squared value $\chi_{\mathrm{c}}^{2}$ for the rate.

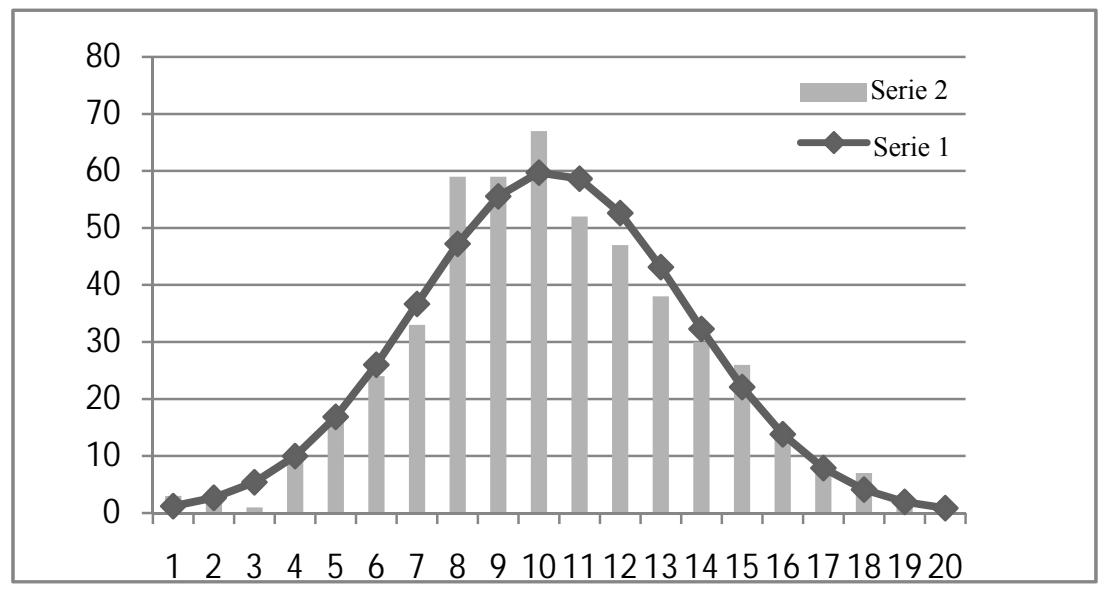

Figure 2. Distribution of the rate and the normal distribution

Description: Serie1: the expected values of the rate under the normal distribution eij. Serie 2 their actual observed values oij.

If the assumption of the normal distribution for the rate must be accepted, then we can calculate a confidence interval:

$$
\text { Average rate } \pm \mathbf{z}_{\mathbf{1 ~ - ~} \mathbf{\alpha} / \mathbf{2}} * \text { standard deviation of the rate }
$$

Thus, for a confidence level of $95 \%$, we saw that $\mathbf{z}_{\mathbf{1 - \alpha} / \mathbf{2}}=1.96$. So we can estimate the $95 \%$ confidence interval for the poverty rate as $11,569 \pm 1.96 * 0,4292=11,569 \pm 0,841232$. Therefore the $95 \%$ confidence interval for the poverty rate is from 10.727768 to 12.410232 .

\section{Conclusion}

This paper develops a new methodology to provide robust interval estimates of the poverty threshold and its rate in a society. The estimate is robust because we can decide a priori of an acceptable level of confidence. Furthermore, the developed methodology is not expensive because it requires taking a single sample from which will be derived 
the laws of probabilities that control the variables needed to assess the threshold and the rate. After this assessment, the simulation takes over for the development of a number of samples that meet the laws of probability distribution derived from the initial sample. The statistical study of the results of these samples can then lead to evaluate confidence intervals for the threshold and rate.

\section{References}

Abel-Smith, B. (1982). The Study and Definition of Poverty: values and aims. Paper presented at the Venise conference on Poverty, 4-5 June 1984.

Atkinson, A. B., \& Cazes, S. (1990). Mesures de la pauvreté et politiques sociales: une étude comparative de la France, de la RFA et du Royaume-Uni. Observations et diagnos- tics économiques, $\mathrm{N}^{\circ} 33$, France (in French).

Belahcen, H. (2005). La lutte contre la pauvreté, cas de l'Algérie. (Magister thesis). Oran University, Algeria; (in Arabic).

Bendraoua, N. (2010). Evaluation et lutte contre la pauvreté: cas de l'Algérie. (magister dissertation). Oran University, Algeria; (in Arabic).

Chanbaz, C. (1997). La pauvreté en France et en Europe. Insee Première N 533.

Concialdi, P. (1998). De nouveaux indicateurs de la pauvreté. Cahiers Francais $n^{\circ} 286$.

Ekert-Jaffe, O., \& Trognon, A. (1994). Evolution du coût de l'enfant avec le revenu: une métho de. In Familles et niveau de vie INED, Paris.

Fisher, G. M. (1997). The Development of the Orshansky Poverty Thresholds and Their Sub- sequent History as the Official U.S. Poverty Measure. Poverty Measurement Working Paper, Census Bureau.

Fishman, G. S. (1978). Principles of Discrete Event Simulation. Wiley, New York.

Foster, J. E., Greer, J., \& Thorbecke, E. (1984). A class of Decomposable Poverty Measures. Econometrica, 52.

Glaude, M., \& Moutardier, M. (1994). Estimation d'échelles d'équivalence pour la France en 1979,1985 et 1989. In Familles et niveau de vie: observation et analyse, INED, Paris.

Goedhart, T., et al. (1977). The Poverty Line: Concept and Measurement. Journal Of Human Resources, 12. http://dx.doi.org/10.2307/145372

Hourriez, J. M., Legendre, N., \& Le Verre, R. (2001). La pauvreté monétaire des ménages de 1970 à 1997. INSEE Premiere $\mathrm{n}^{\circ} 761$.

Kakwani, N. (1980). On a Class of Poverty Measures. Econometrica, 48(2). http://dx.doi.org/10.2307/1911106

Laabas, B. (2001). Poverty Dynamics in Algeria. Paper presented at the ERF/World Bank Conference on Poverty and its Determinants in MENA Countries, Sanaa Yemen.

Lapin, L. L. (1973). Statistics for Modern Business Decisions. Harcourt, Brace and Jovanovich.

O'Higgins, M. (1980). Poverty in Europe - The Subjective Assessment of Poverty Lines: An Evaluation. Bath University.

Orshansky, M. (1965). Counting the Poor: Another Look at the Poverty Profile. Social Security Bulletin, 28.

Ravallion, M. (1992). Poverty Comparisons: A Guide to Concept and Methods World Bank.

Rein, M. (1974). Problems in the Definition and Measurement of Poverty. In P. Townsend (Ed.), The Concept of Poverty. London: Heinemann.

Sen, A. K. (1976). Poverty: an ordinal Approach to Measurement. Econometrica, 44. http://dx.doi.org/10.2307/1912718

Sen, A. K. (1983). Poor, Relatively Speaking. Oxford Economic Paper, 35.

Takayama, N. (1979). Poverty, Income Inequality and Their Measures: Professor Sen's Axiomatic approach reconsidered. Econometrica, 47(3).

Townsend, P. (1962). The Meaning of Poverty. British Journal of Sociology, 13. http://dx.doi.org/10.2307/587266

Van Praag, B. M. S. (1982). A Comparison of Objective and Subjective Measures of Poverty. published in Sarpellon G. (1984).

Watts, H. W. (1968). An Economic Definition of Poverty. In D. P. Moynhihan (Ed.), On understanding Poverty. Basic Books New York. 